\title{
Comparison of professional and laypeople evaluation of nasolabial esthetics following unilateral cleft lip repair
}

\author{
Adekunle Moses Adetayo ${ }^{1,2}$, Modupe Olusola Adetayo ${ }^{3}$, Oguntade Funmi A A $^{1,4}$, \\ Mayowa Solomon Somoye ${ }^{5}$, Michael 0 Adeyemi $^{5}$, Wasiu Lanre Adeyemo ${ }^{5}$
}

Correspondence: Dr. Adekunle Moses Adetayo

Email: adetayoa@babcock.edu.ng

\begin{abstract}
'Department of Surgery, Benjamin Carson Snr School of Medicine, Babcock University, Ogun State, Nigeria, ${ }^{2}$ Department of Surgery, Dental Unit, Babcock University Teaching Hospital, Ogun State, Nigeria, ${ }^{3}$ Department of Biochemistry, Benjamin Carson Snr School of Medicine, Ogun State, Nigeria, ${ }^{4}$ Department of Anaesthesia, Babcock University Teaching Hospital, Ogun State, Nigeria, ${ }^{5}$ Department of Oral and Maxillofacial Surgery, Lagos University Teaching Hospital, Lagos State, Nigeria
\end{abstract}

\section{ABSTRACT}

Objectives: The objective is to know the extent of agreement of clinicians' perception of nasolabial esthetic compared to that of laypeople (parents). Materials and Methods: This was a prospective study of comparison of clinician's perception of nasolabial esthetics with that of laypeople following surgical repair of UCL. Participants were recruited from the Cleft Clinic of the Lagos University Teaching Hospital, and surgical repair of the cleft was performed under general anesthesia. Surgical evaluation was done through direct clinical evaluation using the modified form of the Christofides' criteria by laypeople and professionals. Results: A total of 48 cleft participants were enrolled in the study. The evaluation of the lip by both the laypeople and professionals was similar, and there was no difference $(0.588)$ in their rating. However, there was a significant disagreement $(P=0.001)$ between them in the nose assessment. Conclusion: Neither the solitary opinion of the professionals nor that of the laypeople is satisfactory in the evaluation of facial esthetics; both are equally important, especially in the assessment of nasal esthetics. However, opinion of either the laypeople or the professional might be enough in the evaluation of the lip esthetics.

Key words: Evaluation, laypeople, professionals, unilateral cleft lip and palate

\section{INTRODUCTION}

Clefts of the lip and palate are known to be the most common craniofacial congenital disabilities in human, with birth prevalence ranging from 1 in 500 to 1 in 2000 depending on the population. ${ }^{[1,2]}$ Facial disfigurement with its consequent reduction in

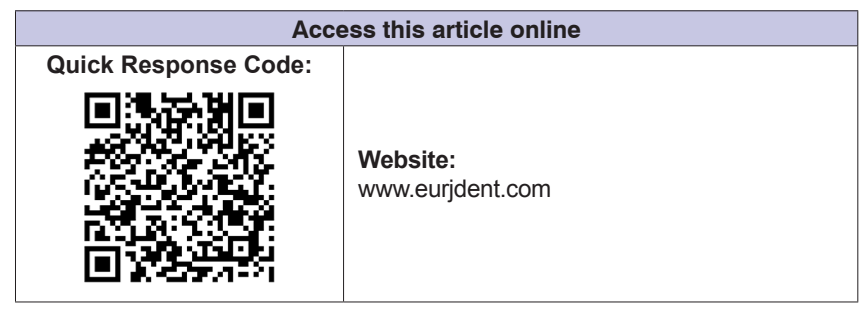

quality of life is one of the major handicaps suffered by the affected person, apart from other problems such as difficulty with feeding, ear infection, and speech. ${ }^{[3]}$

This is an open access journal, and articles are distributed under the terms of the Creative Commons Attribution-NonCommercial-ShareAlike 4.0 License, which allows others to remix, tweak, and build upon the work non-commercially, as long as appropriate credit is given and the new creations are licensed under the identical terms.

For reprints contact: reprints@medknow.com

How to cite this article: Adetayo $\mathrm{AM}$, Adetayo MO, Funmi $\mathrm{AO}$ Somoye MS, Adeyemi MO, Adeyemo WL. Comparison of professional and laypeople evaluation of nasolabial esthetics following unilateral cleft lip repair. Eur J Dent 2018;12:516-22.

DOI: 10.4103/ejd.ejd_31_18 
Surgical treatment of the unilateral cleft lip (UCL) and palate is well documented to be very important as the esthetic and symmetry of the cleft side with the opposite side improved significantly after repair. ${ }^{[4]}$ However, the range of outcome of the surgical repair of the cleft lip and palate can be very wide. The differences in the outcome of surgical repair may be due to disparity in the arrangement of treatments (in patient with cleft lip, alveolus, and palate), timing and technique of treatment, and organization and delivery of care, as well as in the skills and experience of the surgeons involved in cleft repair. ${ }^{[5]}$ In view of this wide range of outcome, assessment of surgical repair is essential to allow for identification and implementation of the highest possible principles in cleft management because inadequate correction of facial esthetics, in particular, nasolabial symmetry, is thought to be a source of emotional distress and dissatisfaction among people affected with cleft lip and palate. ${ }^{[6]}$ The primary surgical repair of the nasolabial area is, therefore, of great importance, to obtain an acceptable correction of the cleft deformity. ${ }^{[7]}$

The methods described for the evaluation of nasolabial appearance have been classified into qualitative (subjective) and quantitative (objective). ${ }^{[8]}$ Subjective assessment is usually esthetic perception among individuals involved in the treatment process, namely, clinicians, patients, and their parents. ${ }^{[9,10]}$ The patients' satisfaction with their own appearance could be considered as most important because it is regarded as a crucial requirement for healthy psychosocial development, especially in adolescents, when facial esthetics are key to self-perception and self-esteem. ${ }^{[10]}$ It is also paramount in requesting for further surgery to improve on patients' perceived quality of life. ${ }^{[11]}$ Notwithstanding, the opinion and support of laypeople such as friends and peers have been shown to also have an effect on the psychological well-being of an individual. ${ }^{[12]}$ Similarly, clinicians' opinion about facial appearance may have important implications for the management as they may affect patients' and parents' perceptions of the need for treatment.

Researchers in the field of facial appearance have attempted to determine whether the treating clinicians, the patients, and the lay public groups agree in their perception of acceptable facial appearance of individuals with cleft lip and palate. ${ }^{[9]}$ There seems to be a convergence of opinions that clinicians and laypeople score the facial appearance of the cleft lip and palate patients consistently lower than individuals without cleft; ${ }^{[13]}$ however, when assessing the facial esthetics of individuals affected with clefts, there are conflicting opinions between laypeople and professionals. ${ }^{[12]}$ Some studies seemed to indicate that clinicians and laypeople are in agreement, ${ }^{[14-19]}$ whereas others gave various degrees of disharmony between the clinicians and laypeople. ${ }^{[6,10,20-22]}$

A better understanding of the differences in perceptions of facial esthetics between professional members of a cleft team, laypersons, and cleft individuals would be an important tool in cleft treatment planning, discussion of outcomes of surgical repair with the patient, as well as management of patient expectations so as to achieve optimal outcome after surgical repair and also maximum patient satisfaction. Therefore, this study attempted to know the extent of agreement of clinicians' perception of nasolabial esthetic compared to that of laypeople (parents).

\section{MATERIALS AND METHODS}

This study was carried out at the Department of Oral and Maxillofacial Surgery, Lagos University Teaching Hospital, Idi-Araba, Lagos, from January 1, 2013 , to July 31, 2014. This was a prospective study of comparison of professionals' perception of nasolabial esthetics with that of laypeople following surgical repair of UCL. Participants were recruited from the Cleft Clinic of the Lagos University Teaching Hospital. All consecutive participants with UCL who presented during the study were included, while participants with syndromic cleft of the lip and/or palate or who required cleft lip revision following primary cleft lip repair or who were not fit for general anesthesia were excluded from the study. Detailed information and explanations of the study were given to parents or guardians, and thereafter, written informed consents were obtained.

Surgical repair was done under general anesthesia with endotracheal intubation. The surgical outcome was assessed using qualitative method. The qualitative method was a modified form of the criteria described by Christofides et al. ${ }^{[23]}$ [Appendices I and II]. This evaluation was carried out by both the laypeople (parents and guardian) [Appendix I] and clinicians [Appendix II]. The scoring indices essentially assessed the residual lip scar and the nose.

The evaluation by the clinicians was carried out by two experienced surgeons (different from the operating 
surgeons) and the researcher. Initially, the assessment was done independently and then together by the three clinicians to resolve any differences in their results. The final results were reached by consensus. The three clinicians met before the commencement of the project to study the modalities of the scoring index. This evaluation was done by means of direct clinical evaluation using the modified form of the criteria (scar transgression of the philtral ridges, symmetry of nostrils, centrality of the columella, thickness of the lip scar, thickness of the scar at the nasal sill, peaking, and notching) as described by Christofides et al. ${ }^{[23]}$ and as shown in the evaluation form [Appendix II].

For the second part of the assessment, the parent/guardian completed a questionnaire to assess satisfaction with the treatment of his/her ward. The questionnaire was interpreted to the parent/guardian where he/she was not literate. The questionnaire consisted of the evaluation of satisfaction with lip scar and nose appearance. The color, shape, and thickness of the scar were used to assess the residual lip scar by the patients/guardians [Appendix I], while the presence or absence of flattening of the nose at the cleft side as well as deviation of the columella was used to assess the nose [Appendix I].

The assessments were weighted and scored. On the questions 1-3 under the participant/guardian questionnaire that has "very happy, happy, okay, and unhappy," choosing very happy or happy was scored as 0 , while choosing okay or unhappy was rated as 1 . On the fourth question (the scar that bothers most), choosing "upper part close to nose" or "lower part close to lip" attracted 1 point while the middle part attracted 0 point. The questions with either yes or no (positive or negative responses) were rated with " 1 " for yes/presence/positive response and " 0 " for no/absence/negative response. On "thickness of scar" and "thickness of scar at the nostril sill," level with the surrounding attracted " 0 " score while elevated or depressed attracted " 1 " score.

\section{Statistical analysis}

An inter-rater reliability analysis using the Cohen's kappa statistic was performed to determine coherence among raters (The inter-rater reliability for the raters was $0.85,95 \%$ confidential interval).

The scores for both the subjective/parents' part and the assessors' part were collated for each participant. Proportions of these scores were also calculated, i.e., scores obtained divided by maximum scores obtainable in each part, to get the absolute values. The higher the score, the poorer the esthetics of the lip or nose parameter assessed, and vice versa. Student's $t$-test and Pearson's correlation analysis were used to find the extent of comparability of both the participant/parents' and assessors' assessment of the lips and nose. A statistical significance level of $P \leq 0.05$ was used.

\section{RESULTS}

A total of 48 participants were enrolled for the study. In the assessment of the lip by the laypeople, the majority $(60.4 \%)$ gave low figures to most of the parameters of the lip indicating very good esthetics. A similar pattern was also observed with the professional assessment [Tables $1 \mathrm{a}$ and 2a]. There was no difference between the assessment of the laypeople and that of the professional $(P=0.588)$ [Table 3a].

In the assessment of the nose, laypeople gave higher scores to the parameters of the nose than did the professionals [Tables $1 \mathrm{~b}$ and $2 \mathrm{~b}$ ]. The comparison showed a significant difference between laypeople and the professionals $(P=0.001)$ [Tables $3 b]$.

\section{DISCUSSION}

The aim of this study was to evaluate whether there are differences in the evaluation of facial esthetics of treated cleft participants by clinician and laypeople. Literature is inconclusive on whether clinicians and laypeople agree

\begin{tabular}{|c|c|c|}
\hline & Score & Frequency (\%) \\
\hline \multirow[t]{3}{*}{ Scar thickness } & 0 & $42(87.5)$ \\
\hline & 1 & $6(12.5)$ \\
\hline & Total & $48(100)$ \\
\hline \multirow[t]{3}{*}{ Scar width } & 0 & $41(85.4)$ \\
\hline & 1 & $7(14.6)$ \\
\hline & Total & $48(100)$ \\
\hline \multirow[t]{3}{*}{ Cupid's bow } & 0 & $25(52.1)$ \\
\hline & 1 & $23(47.9)$ \\
\hline & Total & $48(100)$ \\
\hline \multirow[t]{3}{*}{ Scar that bothers most } & 0 & $8(16.7)$ \\
\hline & 1 & $40(83.3)$ \\
\hline & Total & $48(100)$ \\
\hline
\end{tabular}

\begin{tabular}{llc}
\multicolumn{3}{l}{ Table 1b: Laypeople assessment of the nose } \\
\hline & Score & Frequency (\%) \\
\hline Flattening of the nose at cleft side & 0 & $9(18.8)$ \\
& 1 & $39(81.2)$ \\
Columella deviation & Total & $48(100)$ \\
& 0 & $15(31.3)$ \\
& 1 & $33(68.7)$ \\
& Total & $48(100)$ \\
\hline
\end{tabular}




\begin{tabular}{llc}
\multicolumn{3}{l}{ Table 2a: Professional assessment of the lip } \\
\hline & Score & Frequency (\%) \\
\hline Scar thickness & 0 & $26(54.2)$ \\
& 1 & $22(45.8)$ \\
Scar thickness at nostril sill & Total & $48(100)$ \\
& 0 & $29(60.4)$ \\
Scar transgression of philtrum & 1 & $19(39.6)$ \\
& Total & $48(100)$ \\
Peaking & 0 & $23(47.9)$ \\
& 1 & $25(52.1)$ \\
Notching & Total & $48(100)$ \\
& 0 & $29(60.4)$ \\
& 1 & $19(39.6)$ \\
Keloid/hypertrophic scar & Total & $48(100)$ \\
& 0 & $34(70.8)$ \\
& 1 & $14(29.2)$ \\
& Total & $48(100)$ \\
& 0 & $31(81.3)$ \\
& 1 & $17(18.7)$ \\
& Total & $48(100)$ \\
\hline
\end{tabular}

\begin{tabular}{llc}
\multicolumn{3}{l}{ Table 2b: Professional assessment of the nose } \\
\hline & Score & Frequency (\%) \\
\hline Centrality of columella & 0 & $34(70.8)$ \\
& 1 & $14(29.2)$ \\
Alae on the cleft side & Total & $48(100)$ \\
& 0 & $22(45.8)$ \\
& 1 & $26(54.2)$ \\
& Total & $48(100)$ \\
\hline
\end{tabular}

\begin{tabular}{|c|c|c|c|}
\hline & Mean $\pm S D$ & Correlation & $P$ (t-test) \\
\hline Laypeople & $0.40 \pm 0.23$ & 0.34 & 0.588 \\
\hline Professional & $0.37 \pm 0.23$ & & \\
\hline
\end{tabular}

\begin{tabular}{|c|c|c|c|}
\hline & Mean $\pm S D$ & Correlation & $P(t$-test $)$ \\
\hline Laypeople & $0.75 \pm 0.39$ & 0.44 & 0.001 \\
\hline Professional & $0.42 \pm 0.40$ & & \\
\hline
\end{tabular}

in their assessment of facial esthetics in participants with repaired cleft lip and palate. Some are of the opinion that clinicians are more likely to rate participants with the cleft lip and palate better as found out by Thittiwong et al., ${ }^{[10]}$ Sinko et al., ${ }^{[19]}$ and Marcusson et al..$^{[24]}$ or worse as found out by Gkantidis et al., ${ }^{[6]}$ Chung et al., ${ }^{[11]}$ Foo et al., ${ }^{[22]}$ and Trottman et al. ${ }^{[25]}$ than do the laypeople.

In this study, it is interesting to know that the facial esthetic rating of the lip by the clinicians and the laypeople was similar. This, however, is similar to the findings of Lo et al., ${ }^{[18]}$ Tobiasen, ${ }^{[26]}$ Al-Omari et al., ${ }^{[27]}$ and Prahl et al. ${ }^{[28]}$ but is different from the reports by Eichenberger et al., ${ }^{[13]}$ Thittiwong et al., ${ }^{[10]}$ and Foo et al. ${ }^{[22]}$ A plausible explanation for the difference in the findings might be because laypeople and professionals assessed different stimulus media, two-dimensional (2D) stimulus (photograph), and clinical evaluation in these studies, while clinical evaluation was used for the laypeople and professional assessment in our study. Photographic evaluation has been reported to have poor agreement with clinical evaluation because of variations in magnification. ${ }^{[27,29]}$ However, according to Al-Omari et al., ${ }^{[27]}$ when the laypeople and professional rated live participants or a 3D media, no difference was found in their rating of nasolabial esthetics. ${ }^{[27]}$

Personal bias has also been found to be a reason for poor agreement on lip evaluation among surgeons. ${ }^{[10]}$ The use of a panel of judges' assessment scores to generate a single consensus score for each case has been recommended to remove the interobserver bias and also to improve reliability. ${ }^{[27,30,31]}$ For this reason, the consensus score of three clinician ratings was used in our study.

In the evaluation of the nose, the laypeople rated the nose to be of poorer esthetics than of the professionals. This finding is in consonance with those of Thittiwong et al., ${ }^{[10]}$ Eichenberger et al., ${ }^{[13]}$ Papamanou et al., ${ }^{[32]}$ and Mani et al. ${ }^{[33]}$ This is, however, contrary to a widely held assumption that professionals, due to their training, tend to be more critical, tend to discriminate fine differences in the degree of impairment, and therefore, tend to rate nasal esthetics poorer than do laypeople. ${ }^{[9]}$ This assumption is also supported by the findings of Chung et al., ${ }^{[11]}$ Eliason et al., ${ }^{[21]}$ Foo et al., ${ }^{[22]}$ and Offert et al. ${ }^{[34]}$ A possible explanation for the difference of our finding from these other studies may be the homogeneity of our professional raters. Raters from different professions have been said to differ in their assessment of facial esthetics in individuals with the cleft lip and palate. ${ }^{[13]}$ Surgical professionals, as were the raters in our study, are experienced in the surgical corrections of clefts and so may rate the nasal esthetics higher in view of the potential complications and surgical difficulties that may ensue in achieving optimal esthetic results. ${ }^{[22]}$ In view of different ratings from different professionals, Gkantidis et al. ${ }^{[6]}$ opined that the professionals should be divided into separate groups according to their disciplines, if homogeneity cannot be achieved, to reduce professional bias. ${ }^{[6]}$ 
These findings in this study are essential in the decision-making process, especially for secondary surgical repairs. The factors involved in this decision-making are usually a combination of the patient's preference, achievability of his or her expectations, surgical feasibility, and what is obtainable within the patient's health-care system. ${ }^{[33]}$ While the clinicians and patients/relatives' opinions may not differ on the outcome of labial repair, a disagreement, however, might occur when discussing that of the nose. Hence, the patients and/or relatives should be educated on the possible outcome of the nasal repair with emphasis on the reconstructive challenge associated with nasal deformity of the cleft lip and palate as pointed out by Horswell et al..$^{[35]}$ and Nollet et al. ${ }^{[31]}$

\section{CONCLUSION}

Neither the solitary opinion of the professionals nor that of the laypeople is satisfactory in the evaluation of facial esthetics; both are equally important, especially in the assessment of nasal esthetics. However, opinion of either the laypeople or the professional might be enough in the evaluation of the lip esthetics.

The patient, however, in addition, professionals, and laypeople may also indirectly affect the decision for further surgery.

\section{Financial support and sponsorship Nil.}

\section{Conflicts of interest}

There are no conflicts of interest.

\section{REFERENCES}

1. Marazita ML, Mooney MP. Current concepts in the embryology and genetics of cleft lip and cleft palate. Clin Plast Surg 2004;31:125-40.

2. Butali A, Adeyemo WL, Mossey PA, Olasoji HO, Onah II, Adebola A, et al. Prevalence of orofacial clefts in Nigeria. Cleft Palate Craniofac J 2014;51:320-5.

3. Nwoku AL Experiences on the surgical repair of unoperated adult cleft patients in Nigeria. Nig Med J 1976;4:417-21.

4. Amaratunga NA. Combining Millard's and Cronin's methods of unilateral cleft lip repair - A comparative study. Asian J Oral Maxillofac Surg 2004;16:5-9.

5. Pieter N. Unilateral cleft lip and palate: Treatment outcome and long term craniofacial growth. Benda Drukkers, Wijchen, Netherlands: Proefschrift Radboud Universiteit Nijmegen; 2006. p. 1-35.

6. Gkantidis N, Papamanou DA, Christou P, Topouzelis N. Aesthetic outcome of cleft lip and palate treatment. Perceptions of patients, families, and health professionals compared to the general public. J Craniomaxillofac Surg 2013;41:e105-10.

7. Rullo R, Carinci F, Mazzarella N, Festa VM, Farina A, Morano D, et al. Delaire's cheilorhinoplasty: Unilateral cleft aesthetic outcome scored according to the EUROCLEFT guidelines. Int J Pediatr
Otorhinolaryngol 2006;70:463-8.

8. Farkas LG, Hajnis K, Posnick JC. Anthropometric and anthroposcopic findings of the nasal and facial region in cleft patients before and after primary lip and palate repair. Cleft Palate Craniofac J 1993;30:1-2.

9. Al-Omari I, Millett DT, Ayoub AF. Methods of assessment of cleft-related facial deformity: A review. Cleft Palate Craniofac J 2005;42:145-56.

10. Thittiwong R, Manosudprasit M, Wangsrimongkol T, Kongsomboon S, Pitiphat W, Chowchuen B, et al. Evaluation of facial appearance among patients with repaired unilateral cleft lip and palate: Comparison of patient- and clinician-ratings of satisfaction. J Med Assoc Thai 2015;98 Suppl 7:S68-76.

11. Chung EH, Borzabadi-Farahani A, Yen SL. Clinicians and laypeople assessment of facial attractiveness in patients with cleft lip and palate treated with LeFort I surgery or late maxillary protraction. Int J Pediatr Otorhinolaryngol 2013;77:1446-50.

12. Zhu S, Jayaraman J, Khambay B. Evaluation of facial appearance in patients with cleft lip and palate by laypeople and professionals: A Systematic literature review. Cleft Palate Craniofac J 2016;53:187-96.

13. Eichenberger M, Staudt CB, Pandis N, Gnoinski W, Eliades T. Facial attractiveness of patients with unilateral cleft lip and palate and of controls assessed by laypersons and professionals. Eur J Orthod 2014;36:284-9.

14. Coghlan BA, Matthews B, Pigott RW. A computer-based method of measuring facial asymmetry. Results from an assessment of the repair of cleft lip deformities. Br J Plast Surg 1987;40:371-6.

15. Cussons PD, Murison MS, Fernandez AE, Pigott RW. A panel based assessment of early versus no nasal correction of the cleft lip nose. Br J Plast Surg 1993;46:7-12.

16. Roberts-Harry D, Stephens CD. Panel perception of facial attractiveness. Br J Orthod 1991;18:152-3.

17. Tobiasen JM, Hiebert JM, Boraz RA. Development of scales of severity of facial cleft impairment. Cleft Palate Craniofac J 1991;28:419-24.

18. Lo LJ, Wong FH, Mardini S, Chen YR, Noordhoff MS. Assessment of bilateral cleft lip nose deformity: A comparison of results as judged by cleft surgeons and laypersons. Plast Reconstr Surg 2002;110:733-8.

19. Sinko K, Jagsch R, Prechtl V, Watzinger F, Hollmann K, Baumann A, et al. Evaluation of esthetic, functional, and quality-of-life outcome in adult cleft lip and palate patients. Cleft Palate Craniofac J 2005;42:355-61.

20. Willams HB. A method of assessing cleft lip repairs: Comparison of LeMesurier and Millard techniques. Plast Reconstr Surg 1968;41:103-7.

21. Eliason MJ, Hardin MA, Olin WH. Factors that influence ratings of facial appearance for children with cleft lip and palate. Cleft Palate Craniofac J 1991;28:190-3.

22. Foo P, Sampson W, Roberts R, Jamieson L, David D. Facial aesthetics and perceived need for further treatment among adults with repaired cleft as assessed by cleft team professionals and laypersons. Eur J Orthod 2013;35:341-6.

23. Christofides E, Potgieter A, Chait L. A long term subjective and objective assessment of the scar in unilateral cleft lip repairs using the Millard technique without revisional surgery. J Plast Reconstr Aesthet Surg 2006;59:380-6.

24. Marcusson A, Paulin G, Östrup L. Facial appearance in adults who had cleft lip and palate treated in childhood. Scand J Plast Reconstr Surg Hand Surg 2002;36:16-23.

25. Trotman CA, Phillips C, Faraway JJ, Ritter K. Association between subjective and objective measures of lip form and function: An exploratory analysis. Cleft Palate Craniofac J 2003;40:241-8.

26. Tobiasen JM. Social judgments of facial deformity. Cleft Palate J 1987;24:323-7.

27. Al-Omari I, Millett DT, Ayoub A, Bock M, Ray A, Dunaway D, et al. An appraisal of three methods of rating facial deformity in patients with repaired complete unilateral cleft lip and palate. Cleft Palate Craniofac J 2003;40:530-7.

28. Prahl C, Prahl-Andersen B, van 't Hof MA, Kuijpers-Jagtman AM. Infant orthopedics and facial appearance: A randomized clinical trial (Dutchcleft). Cleft Palate Craniofac J 2006;43:659-64.

29. Howells DJ, Shaw WC. The validity and reliability of ratings of dental and facial attractiveness for epidemiologic use. Am J Orthod 1985;88:402-8.

30. Asher-McDade C, Roberts C, Shaw WC, Gallager C. Development of a method for rating nasolabial appearance in patients with clefts of the lip and palate. Cleft Palate Craniofac J 1991;28:385-90. 
31. Nollet PJ, Kuijpers-Jagtman AM, Chatzigianni A, Semb G, Shaw WC, Bronkhorst EM, et al. Nasolabial appearance in unilateral cleft lip, alveolus and palate: A comparison with eurocleft. J Craniomaxillofac Surg 2007;35:278-86

32. Papamanou DA, Gkantidis N, Topouzelis N, Christou P. Appreciation of cleft lip and palate treatment outcome by professionals and laypeople. Eur J Orthod 2012;34:553-60.

33. Mani M, Reiser E, Andlin-Sobocki A, Skoog V, Holmström M. Factors related to quality of life and satisfaction with nasal appearance in patients treated for unilateral cleft lip and palate. Cleft Palate Craniofac
J 2013;50:432-9.

34. Offert B, Janiszewska-Olszowska J, Dudkiewicz Z, Brudnicki A, Katsaros C, Fudalej PS, et al. Facial esthetics in children with unilateral cleft lip and palate 3 years after alveolar bonegrafting combined with rhinoplasty between 2 and 4 years of age. Orthod Craniofac Res 2013;16:36-43.

35. Horswell BB, Castiglione CL, Poole AE, Assael LA. The double-reversing Z-plasty in primary palatoplasty: Operative experience and early results. J Oral Maxillofac Surg 1993;51:145-9.

\section{APPENDIX}

\section{Appendices}

\section{Appendix I: Parents/guardian questionnaire}

Please answer the following questions and tick the appropriate boxes below. The aim is to identify your satisfaction with your cleft lip repair. In particular, we want to assess the scar and wish to ascertain what bothers most.

\begin{tabular}{|l|l|}
\hline 1 & Very satisfied (very happy) \\
\hline 2 & Does not bother me much (happy) \\
\hline 3 & Could have been better (okay) \\
\hline 4 & Not satisfied at all (unhappy) \\
\hline
\end{tabular}

\section{Lip}

1. Are you satisfied with the thickness (amount of bulging above the skin) of the scar?

\begin{tabular}{|l|l|l|l|l|l|l|}
\hline 1 & & 2 & & 3 & & 4 \\
\hline
\end{tabular}

2. Are you satisfied with the width of the scar?

\begin{tabular}{|l|l|l|l|l|l|l|}
\hline 1 & & 2 & & 3 & & 4 \\
\hline
\end{tabular}

3. Are you satisfied with the Cupid's bow?

\begin{tabular}{|l|l|l|l|l|l|l|}
\hline 1 & & 2 & & 3 & & 4 \\
\hline
\end{tabular}

4. What part of the scar bothers you the most?

\begin{tabular}{|l|l|}
\hline Upper part close to nose & \\
\hline Middle part & \\
\hline Lower part close to lip & \\
\hline
\end{tabular}

Nose

1. Presence or absence of flattening of nostril at the cleft side?

\begin{tabular}{|l|l|}
\hline Yes & \\
\hline No & \\
\hline
\end{tabular}

2. Deviation of the columella?

\begin{tabular}{|l|l|}
\hline Yes & \\
\hline No & \\
\hline
\end{tabular}




\section{Appendix II: Assessors evaluation form}

\section{Lip}

Thickness of scar

\begin{tabular}{|l|l|}
\hline Level with the surrounding skin & \\
\hline Depressed & \\
\hline Elevated & \\
\hline
\end{tabular}

Scar transgression of anatomical boundary (philtral ridge)

\begin{tabular}{|l|l|}
\hline Yes & \\
\hline No & \\
\hline
\end{tabular}

\section{Peaking}

\begin{tabular}{|l|l|}
\hline Yes & \\
\hline No & \\
\hline
\end{tabular}

Notching

\begin{tabular}{|l|l|}
\hline Yes & \\
\hline No & \\
\hline
\end{tabular}

Keloid/hypertrophic scar

\begin{tabular}{|l|l|}
\hline Yes & \\
\hline No & \\
\hline
\end{tabular}

Thickness of scar at the nostril sill

\begin{tabular}{|l|l|}
\hline Level with the surrounding skin & \\
\hline Depressed & \\
\hline Elevated & \\
\hline
\end{tabular}

Nose

Centrality of columella

\begin{tabular}{|l|l|}
\hline Central & \\
\hline Deviated & \\
\hline
\end{tabular}

Alae on the cleft side

\begin{tabular}{|l|l|}
\hline Normal & \\
\hline Flattened & \\
\hline
\end{tabular}

